\title{
Effectiveness of transcranial direct current stimulation on pain and function in knee osteoarthritis: a systematic review with meta-analysis based on PRISMA guidelines
}

\author{
DOI: https://doi.org/10.5114/pq.2020.100282
}

\author{
Rekha Chaturvedi, Sivachidambaram Kulandaivelan, Shabnam Joshi \\ Department of Physiotherapy, Guru Jambheshwar University of Science and Technology, Hisar, India
}

\begin{abstract}
Introduction. To evaluate the effectiveness of transcranial direct current stimulation (tDCS) on pain and function in patients with knee osteoarthritis $(\mathrm{OA})$.

Methods. The meta-analysis data source were PubMed (MEDLINE) and Cochrane (Central). Randomized controlled trials comparing active tDCS (in combination with other interventions or alone in knee OA patients) with sham tDCS published in English till July 2019 were analysed. The outcome measures were pain intensity (visual analogue scale and numeric rating scale) and function (Western Ontario and McMaster Universities Osteoarthritis Index [WOMAC]). Mean difference with 95\% confidence interval for the active tDCS and sham groups were investigated.

Results. Four articles with 171 patients were included in the qualitative systematic review and 2 articles with 55 patients were included in the quantitative meta-analysis. The results revealed a statistically significant reduction in pain (visual analogue scale) in the active tDCS group compared with the sham group $(Z=7.32, p<0.00001)$ and a significant improvement in WOMAC scores $(Z=2.31, p=0.02)$, with high heterogeneity of $83 \%$.

Conclusions. There is a significant improvement in pain and function in patients with knee OA after the application of active tDCS either alone or in combination. However, more studies are required to confirm the effectiveness of tDCS in knee OA. Owing to the promising results of tDCS in various pain conditions and in knee OA, it can be seen as a future tool for managing pain in the field of physiotherapy.

Key words: transcranial direct current stimulation, pain, functional improvement, WOMAC, meta-analysis
\end{abstract}

\section{Introduction}

The Global Burden of Disease 2010 study revealed that knee osteoarthritis (OA) was the prominent cause of disability and was ranked $11^{\text {th }}$ highest contributor of global disability [1]. The prevalence of knee OA is $28.7 \%$ in India [2]; around $20 \%$ of the population above 30 years of age experience knee symptoms in India [3]. Persistent pain is a common problem associated with knee OA that causes maladaptive changes in the brain and spinal cord $[4,5]$. Analogous findings have been described in patients with chronic regional pain syndrome and low back pain, thereby suggesting a positive correlation of a decrease in the grey matter and the chronicity of pain [6]. Recent literature has also indicated that patients with knee OA have altered central pain processing [7-10] and increased blood-oxygen-level-dependent activity in response to painful stimuli [11-13]. Also, the persistent inflammatory processes in the joint and anatomic lesions cause significant atrophy in grey matter in $\mathrm{OA}$ patients $[14,15]$. All these findings reinforce the need for using a treatment intervention that has a potential to modulate the central pain processing system. Therefore, non-invasive brain stimulation techniques have gained considerable interest among researchers to treat chronic pain conditions.

Transcranial direct current stimulation (tDCS) is a simple and safe non-invasive brain stimulation technique that involves the application of weak electrical currents to the scalp with the use of a surface electrode [16], which results in al- tering the excitability of the motor cortex [17-19] by increasing the firing of neurons underneath the electrodes. The magnitude of change in excitability depends on various factors, such as positioning of the electrodes, intensity of the current applied, and duration of the application. Anodal stimulation of primary motor cortex raises the cortical excitability by increasing the neuronal resting membrane potential, while cathodal stimulation reverses the effect by decreasing the neuronal firing. Various studies have also suggested an analgesic effect with anodal stimulation via modulation of neuronal membrane channels and thus producing local and distant plastic changes in the brain, thereby demonstrating the potential of tDCS to treat a variety of chronic pain conditions. The effectiveness of tDCS has already been proved in different chronic pain conditions like fibromyalgia, low back pain, etc. [20-22]. However, there is a scarcity of literature that describes the effectiveness of tDCS in musculoskeletal conditions like OA.

Usually, transcutaneous electrical nerve stimulation has been used to relieve pain through the pain gate mechanism [23]. However, recent physical therapy guidelines for knee OA put more emphasis on exercises and less on electrotherapy interventions like transcutaneous electrical nerve stimulation [24, 25]. Hence, tDCS could be used to modulate pain through the central pain mechanism. Moreover, literature advocates the use of tDCS along with exercises to produce pronounced impact owing to the motor learning through the priming effect in knee OA patients [26]. Hence, the effective-

Correspondence address: Rekha Chaturvedi, Department of Physiotherapy, Guru Jambheshwar University of Science and Technology, Hisar-125001, Haryana, India, e-mail: rekhachaturvedi85@gmail.com 
ness of tDCS must be explored further to establish the role of tDCS in treating musculoskeletal pain with altered central pain processing. Therefore, the primary objective of this review is to encapsulate the data available on the effectiveness of tDCS in knee OA on pain and function in order to evaluate the efficacy of this therapy and verify if tDCS utilization can be explored as a new approach to treat OA.

\section{Subjects and methods}

\section{Eligibility criteria}

This meta-analysis and systematic review was performed in accordance with the PRISMA guidelines. Articles comparing the effectiveness of active tDCS with sham tDCS and following the diagnostic criteria for OA provided by the American College of Rheumatology (1990 or 2010 ACR) [27] were included. All published articles in English till July 2019 were eligible. The search was restricted to randomized controlled trials performed in humans. This systematic review was conducted in July 2019; the use of tDCS is recently evolving very rapidly and hence the number of articles available in databases is very low, so the systematic review was not recorded in the PROSPERO register.

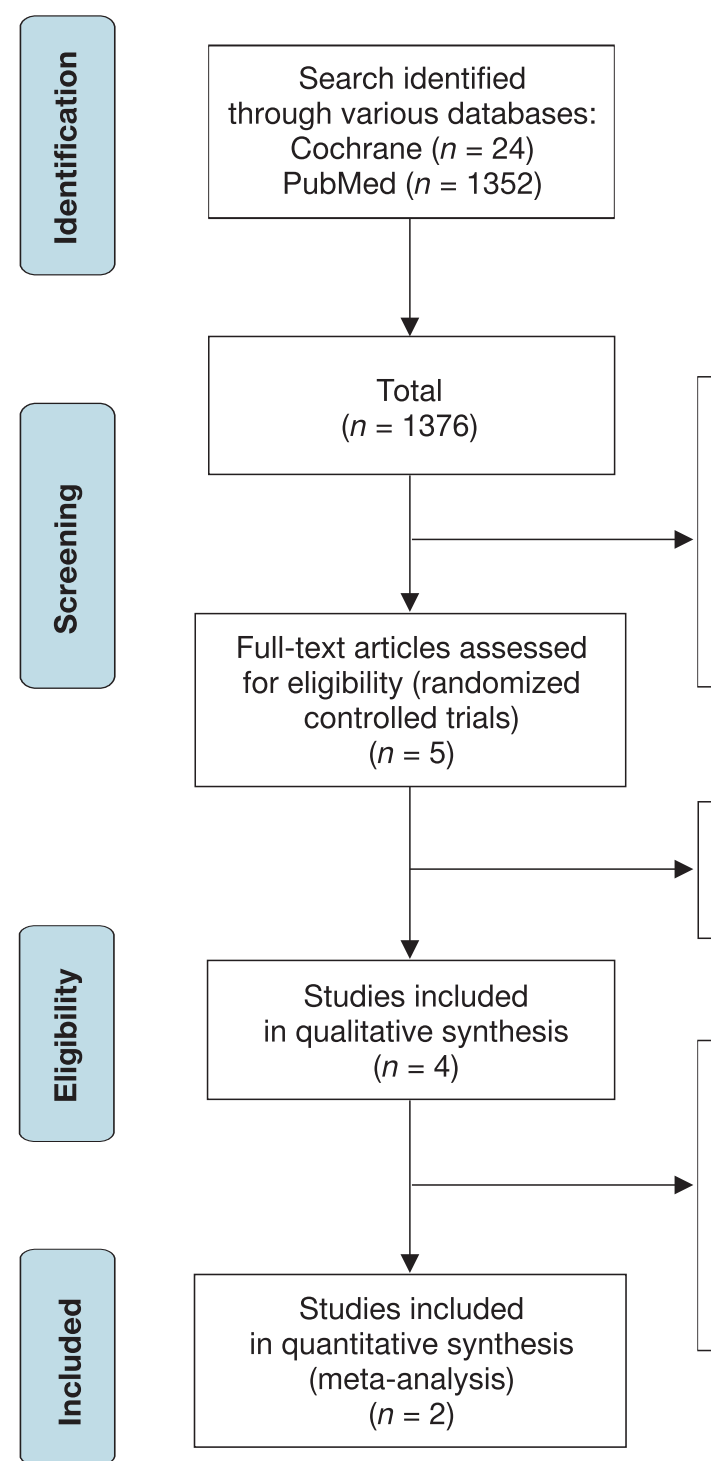

\section{Information sources}

Information was collected from 2 electronic databases: PubMed (MEDLINE) and Cochrane (Central) from inception to July 2019.

\section{Search strategy}

For searching the relevant literature in PubMed, the following keywords were used: "Transcranial direct current stimulation" OR "tDCS" AND "Osteoarthritis" OR "OA" AND "knee" for the title/abstract in the advanced search options; during the filter search, "Clinical trial" and "Humans" were used to scrutinize the articles. For searching in Cochrane, ("Transcranial direct current stimulation"): ti, ab, kw OR ("tDCS"): ti, ab, kw AND ("Osteoarthritis"): ti, ab, kw were used.

\section{Study selection}

We applied the PICOS strategy where the population was knee OA. The intervention was tDCS; the comparator group was either active tDCS or sham (placebo) tDCS or control group; the outcome measures were pain, evaluated either with the visual analogue scale (VAS) or with the numeric rating scale (NRS), and function, assessed with the Western Ontario and McMaster Universities Osteoarthritis Index (WOMAC). Studies which included both active tDCS

\section{Records excluded $(n=1371)$ :}

Criteria:

1. Titles and abstracts $(n=1268)$

2. Study protocol $(n=62)$

3. Registered clinical trials $(n=7)$

4. Other $(n=34)$ 
(in combination with other interventions or in isolation) and sham tDCS in patients with knee OA were selected.

Eligible relevant studies were scrutinized by 2 reviewers (SK and RC) first by the title, then by the title and abstract, and finally by the availability of full text. Studies that were not experimental; that did not provide values of the investigated variables, i.e. pain and function; and that did not refer data in terms of mean and standard deviation were excluded from this systematic review and meta-analysis.

A total of 1352 studies from PubMed and 24 studies from Cochrane were obtained by using the search strategy mentioned above. After the removal of duplicates, 4 studies were selected for the systematic review. Only 2 studies were included in the for meta-analysis; 2 were excluded: 1 article involved significant differences between groups in the baseline values of VAS and WOMAC, and in 1 study the required data could not be retrieved (it presented only values of pressure pain threshold and not the desired VAS and WOMAC scores). Figure 1 illustrates the PRISMA flow chart for the selection of the studies.

\section{Data collection process}

Two authors (RC and SK) autonomously searched and extracted the data in accordance with the MeSH terms and related keywords. The extracted information was crosschecked for any disparity. Any disagreement was resolved through discussion with SJ and the decision of SJ was final.

To find out the effectiveness of the intervention, mean and standard deviation of pain (VAS or NRS) and function (WOMAC) along with other sample characteristics like age, height, weight, body mass index (BMI) were extracted from both the experimental and control group. Data concerning author, year, continent/country, the total number of subjects for both the experimental and control group were also extracted and compared.

\section{Risk bias in individual studies}

Methodological study quality was assessed with the Physiotherapy Evidence Database (PEDro) and the Downs and Black checklist for randomized controlled trials [28]. Studies were considered of higher quality if they met the criteria for randomization and allocation concealment, assessor blinding, and intention-to-treat analysis. The quality assessment was performed independently by 2 investigators (SK, RC).

\section{Synthesis of results}

This was done by using the Review Manager 5 (RevMan 5) software, which is a Cochrane Collaboration software for systematic reviews and meta-analyses. Mean difference and $95 \%$ confidence interval were computed by entering the data for mean, standard deviation, and total number of subjects for both the active tDCS group and the sham group. Forest plots for pain and WOMAC were also produced with RevMan 5. The significance level was 0.05 . The analysis was performed by 2 independent investigators (SK, SJ).

\section{Ethical approval}

The conducted research is not related to either human or animal use.

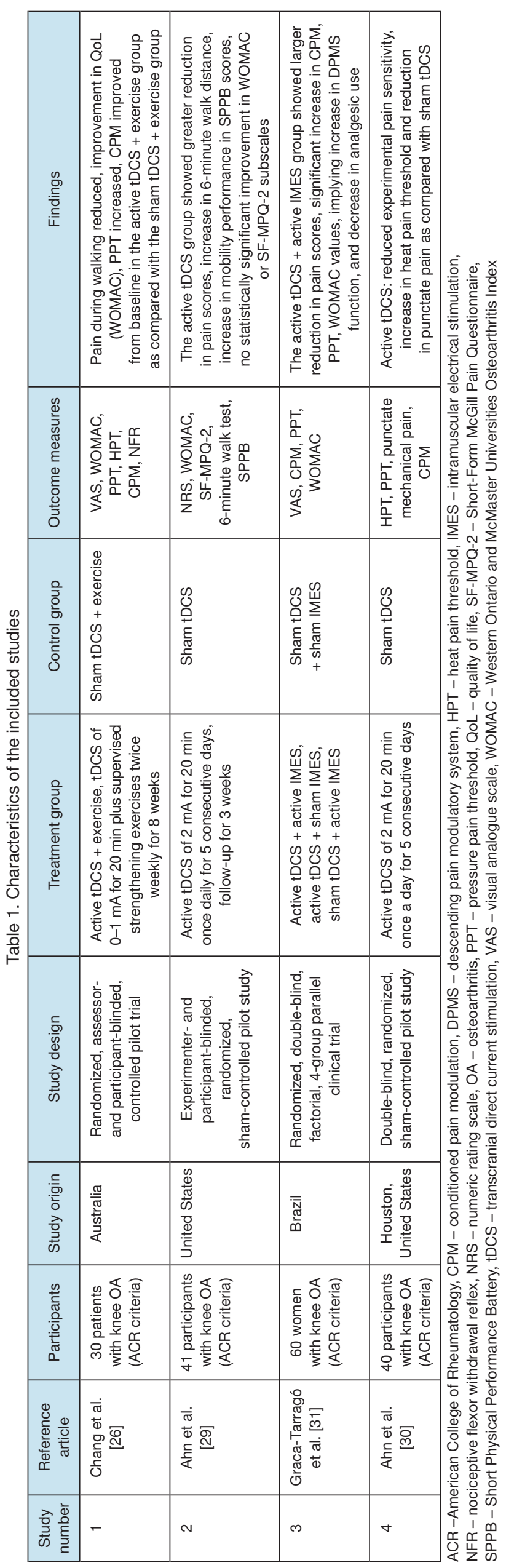


Table 2. Quality assessment of the selected randomized controlled trials with the Physiotherapy Evidence Database (PEDro) scoring (higher score implies higher quality)

\begin{tabular}{|c|c|c|c|c|c|}
\hline $\begin{array}{l}\text { Criterion } \\
\text { number }\end{array}$ & Criteria & $\begin{array}{l}\text { Chang } \\
\text { et al. [26] }\end{array}$ & $\begin{array}{c}\text { Ahn et al. } \\
\text { [29] }\end{array}$ & $\begin{array}{l}\text { Graca- } \\
\text { Tarragó } \\
\text { et al. [31] }\end{array}$ & $\begin{array}{c}\text { Ahn et al. } \\
\text { [30] }\end{array}$ \\
\hline 1 & Specified eligibility criteria & Yes & Yes & Yes & Yes \\
\hline 2 & Random allocation & Yes & Yes & Yes & Yes \\
\hline 3 & Concealed allocation & Yes & Yes & Yes & Yes \\
\hline 4 & Similar baseline & Yes & No & Yes & Yes \\
\hline 5 & Subjects blinding & Yes & Yes & Yes & Yes \\
\hline 6 & Therapists blinding & No & Yes & Yes & Yes \\
\hline 7 & Assessors blinding & Yes & Yes & Yes & Yes \\
\hline 8 & Measures of key outcomes for more than $85 \%$ of subjects & Yes & Yes & Yes & Yes \\
\hline 9 & Intention-to-treat analysis of 1 key outcome & Yes & No & No & No \\
\hline 10 & Between-group statistical comparisons of at least 1 key outcome & Yes & Yes & Yes & Yes \\
\hline 11 & Variability for at least 1 key outcome & Yes & Yes & Yes & Yes \\
\hline \multicolumn{2}{|l|}{ Total } & $10 / 11$ & $9 / 11$ & $10 / 11$ & $10 / 11$ \\
\hline
\end{tabular}

\section{Results}

\section{Study characteristics}

All the studies included in this review were pilot studies investigating 131 patients in total. One study was from Australia [26], 2 from the United States [29, 30], and 1 from Brazil [31]. All these studies used tDCS (either in combination with other intervention or alone) in comparison with a sham group.

The study by Chang et al. [26] involved active tDCS in combination with exercises twice weekly for 8 weeks. Ahn et al. [29] applied only active tDCS and compared it with sham tDCS. The study by da Graca-Tarragó et al. [31] concerned tDCS in combination with intramuscular electrical stimulation. All the studies measured changes in pain (VAS or NRS) and function (WOMAC scale). Table 1 presents the overview of the included studies.

\section{Quality assessment}

Table 2 summarizes the quality of the studies included in this review. Three of them had a PEDro score of 10 out of 11 , depicting their high quality, and one study was scored 9 of 11 . Table 3 summarizes the methodological quality assessment of the included studies in accordance with the Downs and Black checklist.

\section{Risk of bias}

The risk of bias is explained in Figure 2. All the studies included showed a low risk in random sequence generation (selection bias), allocation concealment (selection bias), blinding of participants and personnel (performance bias), blinding of outcome assessment (detection bias), incomplete outcome data (attrition bias), and selective reporting (reporting bias), as well as a high risk in other bias. The overall risk of bias was low in all the included studies.

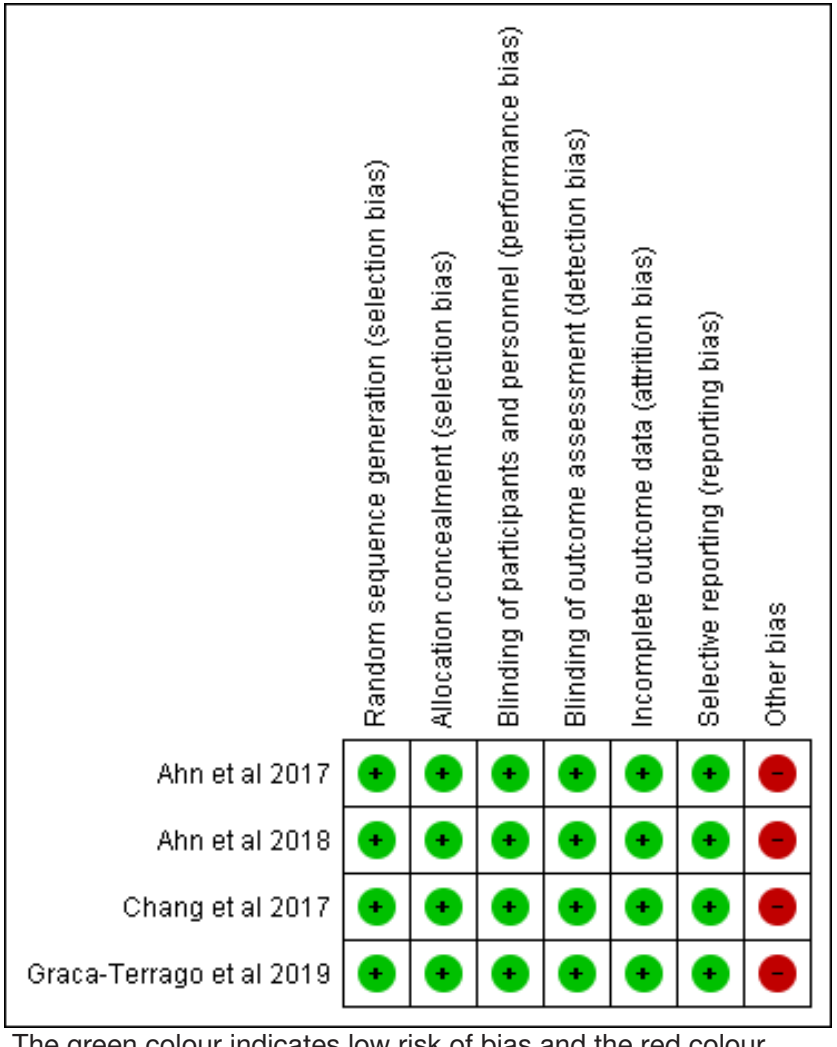

The green colour indicates low risk of bias and the red colour shows high risk of bias

Figure 2. Risk of bias summary

\section{Result summary}

The result of the meta-analysis showed that the reduction in pain was statistically significant in the active tDCS groups as compared with the sham groups $(Z=7.32, p<$ $0.00001)$, with no heterogeneity of the included studies (Figure 3). The meta-analysis also indicates that function improvement was in favour of active tDCS $(Z=2.31, p=0.02)$, with high heterogeneity of $83 \%$ in the included studies (Figure 4). 
Table 3. Downs and Black checklist for assessing the methodological quality of the studies

\begin{tabular}{|c|c|c|c|c|c|}
\hline $\begin{array}{l}\text { Criterion } \\
\text { number }\end{array}$ & Criteria & $\begin{array}{l}\text { Chang } \\
\text { et al. [26] }\end{array}$ & $\begin{array}{c}\text { Ahn et al. } \\
{[29]}\end{array}$ & $\begin{array}{l}\text { Graca- } \\
\text { Tarragó } \\
\text { et al. [31] }\end{array}$ & $\begin{array}{l}\text { Ahn et al. } \\
{[30]}\end{array}$ \\
\hline 1 & $\begin{array}{l}\text { Reporting } \\
\text { Is the hypothesis/aim/objective of the study clearly described? }\end{array}$ & Yes & Yes & Yes & Yes \\
\hline 2 & $\begin{array}{l}\text { Are the main outcomes to be measured clearly described in the Introduction } \\
\text { or Methods section? }\end{array}$ & Yes & Yes & Yes & Yes \\
\hline 3 & Are the characteristics of the patients included in the study clearly described? & Yes & Yes & Yes & Yes \\
\hline 4 & Are the interventions of interest clearly described? & Yes & Yes & Yes & Yes \\
\hline 5 & $\begin{array}{l}\text { Are the distributions of principal confounders in each group of subjects } \\
\text { to be compared clearly described? }\end{array}$ & No & Yes & Yes & Yes \\
\hline 6 & Are the main findings of the study clearly described? & Yes & Yes & Yes & Yes \\
\hline 7 & $\begin{array}{l}\text { Does the study provide estimates of the random variability in the data for the main } \\
\text { outcomes? }\end{array}$ & Yes & Yes & Yes & Yes \\
\hline 8 & $\begin{array}{l}\text { Have all important adverse events that may be a consequence of the intervention } \\
\text { been reported? }\end{array}$ & Yes & Yes & No & Yes \\
\hline 9 & Have the characteristics of patients lost to follow-up been described? & Yes & Yes & Yes & Yes \\
\hline 10 & $\begin{array}{l}\text { Have actual probability values been reported (e.g. } 0.035 \text { rather than }<0.05) \\
\text { for the main outcomes except where the probability value is less than } 0.001 \text { ? }\end{array}$ & Yes & Yes & Yes & Yes \\
\hline 11 & $\begin{array}{l}\text { External validity } \\
\text { Were the subjects asked to participate in the study representative of the entire } \\
\text { population from which they were recruited? }\end{array}$ & Yes & Yes & Yes & Yes \\
\hline 12 & $\begin{array}{l}\text { Were those subjects who were prepared to participate representative } \\
\text { of the entire population from which they were recruited? }\end{array}$ & $\begin{array}{l}\text { Unable to } \\
\text { determine }\end{array}$ & $\begin{array}{l}\text { Unable to } \\
\text { determine }\end{array}$ & $\begin{array}{l}\text { Unable to } \\
\text { determine }\end{array}$ & $\begin{array}{l}\text { Unable to } \\
\text { determine }\end{array}$ \\
\hline 13 & $\begin{array}{l}\text { Were the staff, places, and facilities where the patients were treated representative } \\
\text { of the treatment the majority of patients receive? }\end{array}$ & No & No & $\begin{array}{l}\text { Unable to } \\
\text { determine }\end{array}$ & No \\
\hline 14 & $\begin{array}{l}\text { Internal validity - bias } \\
\text { Was an attempt made to blind study subjects to the intervention they received? }\end{array}$ & Yes & Yes & Yes & Yes \\
\hline 15 & $\begin{array}{l}\text { Was an attempt made to blind those measuring the main outcomes } \\
\text { of the intervention? }\end{array}$ & Yes & Yes & Yes & Yes \\
\hline 16 & If any of the results of the study were based on 'data dredging,' was this made clear? & Yes & Yes & Yes & Yes \\
\hline 17 & $\begin{array}{l}\text { In trials and cohort studies, do the analyses adjust for different lengths of follow-up } \\
\text { of patients, or in case-control studies, is the time between the intervention and out- } \\
\text { come the same for cases and controls? }\end{array}$ & Yes & Yes & Yes & Yes \\
\hline 18 & Were the statistical tests used to assess the main outcomes appropriate? & Yes & Yes & Yes & Yes \\
\hline 19 & Was compliance with the intervention(s) reliable? & Yes & Yes & Yes & Yes \\
\hline 20 & Were the main outcome measures used accurate (valid and reliable)? & Yes & Yes & Yes & Yes \\
\hline 21 & $\begin{array}{l}\text { Internal validity - confounding (selection bias) } \\
\text { Were the patients in different intervention groups (trials and cohort studies) or were } \\
\text { the cases and controls (case-control studies) recruited from the same population? }\end{array}$ & Yes & Yes & Yes & Yes \\
\hline 22 & $\begin{array}{l}\text { Were study subjects in different intervention groups (trials and cohort studies) } \\
\text { or were the cases and controls (case-control studies) recruited over the same period? }\end{array}$ & Yes & Yes & $\begin{array}{l}\text { Unable to } \\
\text { determine }\end{array}$ & Yes \\
\hline 23 & Were study subjects randomized to intervention groups? & Yes & Yes & Yes & Yes \\
\hline 24 & $\begin{array}{l}\text { Was the randomized intervention assignment concealed from both patients } \\
\text { and health care staff until recruitment was complete and irrevocable? }\end{array}$ & Yes & Yes & Yes & Yes \\
\hline 25 & $\begin{array}{l}\text { Was there adequate adjustment for confounding in the analyses from which } \\
\text { the main findings were drawn? }\end{array}$ & Yes & Yes & Yes & Yes \\
\hline 26 & Were losses of patients to follow-up taken into account? & Yes & $\begin{array}{l}\text { Unable to } \\
\text { determine }\end{array}$ & $\begin{array}{l}\text { Unable to } \\
\text { determine }\end{array}$ & $\begin{array}{l}\text { Unable to } \\
\text { determine }\end{array}$ \\
\hline 27 & $\begin{array}{l}\text { Power } \\
\text { Did the study have sufficient power to detect a clinically important effect where } \\
\text { the probability value for a difference being due to chance is less than } 5 \% \text { ? }\end{array}$ & Yes & Yes & Yes & Yes \\
\hline \multicolumn{2}{|l|}{ Total } & $24 / 27$ & $24 / 27$ & $22 / 27$ & $24 / 27$ \\
\hline
\end{tabular}




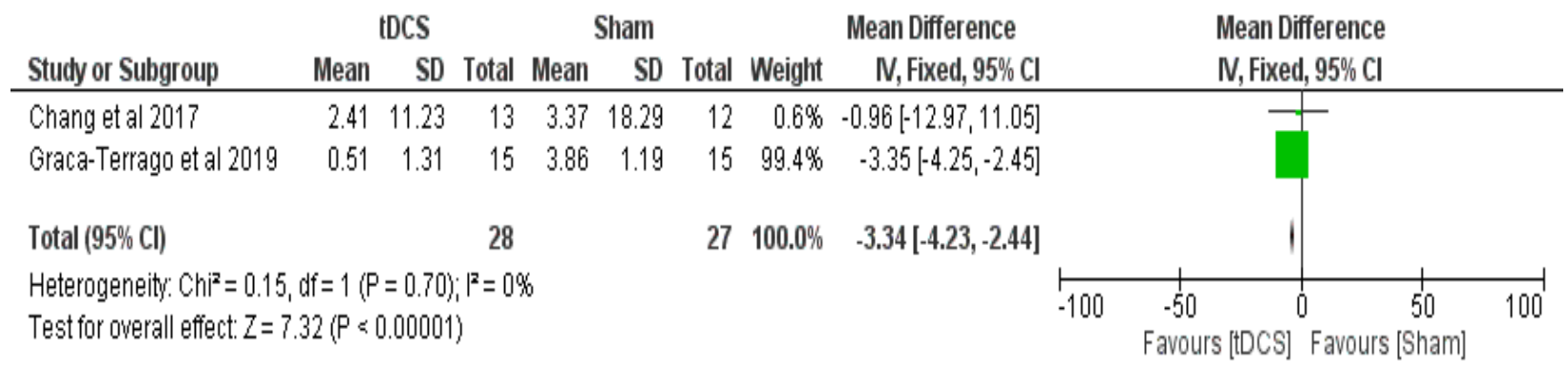

tDCS - transcranial direct current stimulation

Figure 3. Forest plot for pain in patients with knee osteoarthritis

\begin{tabular}{|c|c|c|c|c|c|c|c|c|c|c|c|c|}
\hline \multirow[b]{2}{*}{ Study or Subgroup } & \multicolumn{3}{|c|}{ tDCS } & \multicolumn{3}{|c|}{ Sham } & \multicolumn{3}{|c|}{ Mean Difference } & \multirow{2}{*}{$\begin{array}{l}\text { Mean Difference } \\
\text { IV, Fixed, } 95 \% \mathrm{Cl}\end{array}$} & & \\
\hline & Mean & SD & Total & Mean & SD & Total & Weight & IV, Fixed, $95 \% \mathrm{Cl}$ & & & & \\
\hline Chang et al 2017 & 36.8 & 10.83 & 13 & 39.01 & 15.68 & 12 & $64.6 \%$ & $-2.21[-12.86,8.44]$ & & & & \\
\hline Graca-Terrago et al 2019 & 22.31 & 23.19 & 15 & 46.6 & 16.42 & 15 & $35.4 \%$ & $-24.29[-38.67,-9.91]$ & & - & & \\
\hline Total (95\% Cl) & & & 28 & & & 27 & $100.0 \%$ & $-10.03[-18.59,-1.47]$ & & & & \\
\hline $\begin{array}{l}\text { Heterogeneity: } \mathrm{Ch}^{2}=5.85 \\
\text { Test for overall effect: } \mathrm{Z}=\end{array}$ & $\begin{array}{l}d f=1(P \\
30(P=0\end{array}$ & $\begin{array}{l}=0.02 \\
0.02)\end{array}$ & $1^{2}=83$ & & & & & & -100 & $\begin{array}{cc}-50 & 0 \\
= & =0\end{array}$ & $\begin{array}{l}50 \\
\text { [Sham] }\end{array}$ & $100^{\circ}$ \\
\hline
\end{tabular}

tDCS - transcranial direct current stimulation

Figure 4. Forest plot for function (WOMAC) in patients with knee osteoarthritis

\section{Discussion}

The results of the meta-analysis suggest that there was a statistically significant improvement in pain (VAS) and functional improvement (WOMAC) in the patients with knee OA after the application of active tDCS, whether in combination with other interventions or used in isolation. The results of individual studies included in this review favour the application of active tDCS in improving pain (VAS) and function (WOMAC) in patients with knee OA. It can be inferred from the results of the meta-analysis that tDCS is an effective intervention in knee OA management.

This systematic review includes 4 moderate-to-high quality studies with a low risk of bias. However, the review addresses some limitations, which include a small number of studies $(n=4)$ with small samples (of around 170 patients). The majority of the included studies reported preliminary (pilot study) findings. We also observed high heterogeneity in function, with $\mathrm{I}^{2}$ of $83 \%$. We could not perform sensitivity analysis because of the small sample size. So, in order to generalize the effectiveness of tDCS, more randomized controlled trials with larger sample sizes are required to establish the role of active tDCS in knee OA treatment.

Taking into account the initial promising results of tDCS application in various conditions like low back pain, fibromyalgia, many psychological disorders [19, 20, 25], and, to some extent, knee OA, its effectiveness can be further explored and the use of tDCS can be seen as a potential tool in the management of knee OA.

\section{Disclosure statement}

No author has any financial interest or received any financial benefit from this research.

\section{Conflict of interest}

The authors state no conflict of interest.

\section{References}

1. Cross M, Smith E, Hoy D, Nolte S, Ackerman I, Fransen $\mathrm{M}$, et al. The global burden of hip and knee osteoarthritis: estimates from the Global Burden of Disease 2010 study. Ann Rheum Dis. 2014;73(7):1323-1330; doi: 10.1136/annrheumdis-2013-204763.

2. Pal CP, Singh P, Chaturvedi S, Pruthi KK, Vij A. Epidemiology of knee osteoarthritis in India and related factors. Indian J Orthop. 2016;50(5):518-522; doi: 10.4103/ 0019-5413.189608.

3. Kulandaivelan S, Tigdania N, Ateef M, Chaturvedi R, Joshi S, Malik A, et al. Prevalence of knee pain and its correlates with specific emphasis on CVD risk factors in Hisar urban population. Int J Clin Rheumatol. 2017;12(4): 91-96.

4. Howard MA, Sanders D, Krause K, O'Muircheartaigh J, Fotopoulou A, ZelayaF, et al. Alterations in resting-state regional cerebral blood flow demonstrate ongoing pain in osteoarthritis: an arterial spin-labeled magnetic resonance imaging study. Arthritis Rheum. 2012;64(12): 3936-3946; doi: 10.1002/art.37685.

5. Mao CP, Bai ZL, Zhang XN, Zhang QJ, Zhang L. Abnormal subcortical brain morphology in patients with knee osteoarthritis: a cross-sectional study. Front Aging Neurosci. 2016;8:3; doi: 10.3389/fnagi.2016.00003.

6. Wood PB. Variations in brain gray matter associated with chronic pain. Curr Rheumatol Rep. 2010;12(6):462-469; doi: 10.1007/s11926-010-0129-7.

7. Latremoliere A, Woolf CJ. Central sensitization: a generator of pain hypersensitivity by central neural plasticity. J Pain. 2009;10(9):895-926; doi: 10.1016/j.jpain.2009. 06.012.

8. Finan PH, Buenaver LF, Bounds SC, Hussain S, Park RJ, Haque UJ, et al. Discordance between pain and radiographic severity in knee osteoarthritis: findings from quantitative sensory testing of central sensitization. Arthritis Rheum. 2013;65(2):363-372; doi: 10.1002/art. 34646. 
9. Rakel B, Vance C, Zimmerman MB, Petsas-Blodgett N, Amendola A, Sluka KA. Mechanical hyperalgesia and reduced quality of life occur in people with mild knee osteoarthritis pain. Clin J Pain. 2015;31(4):315-322; doi: 10.1097/AJP.0000000000000116.

10. Neogi T, Guermazi A, Roemer F, Nevitt MC, Scholz J, Arendt-Nielsen L, et al. Association of joint inflammation with pain sensitization in knee osteoarthritis: the Multicenter Osteoarthritis Study. Arthritis Rheumatol. 2016; 68(3):654-661; doi: 10.1002/art.39488.

11. Gwilym SE, Keltner JR, Warnaby CE, Carr AJ, Chizh B, Chessell I, et al. Psychophysical and functional imaging evidence supporting the presence of central sensitization in a cohort of osteoarthritis patients. Arthritis Rheum. 2009;61(9):1226-1234; doi: 10.1002/art.24837.

12. Hiramatsu T, Nakanishi K, Yoshimura S, Yoshino A, Adachi N, Okamoto $\mathrm{Y}$, et al. The dorsolateral prefrontal network is involved in pain perception in knee osteoarthritis patients. Neurosci Lett. 2014;581:109-114; doi: 10.1016/j.neulet.2014.08.027.

13. Sofat N, Smee C, Hermansson M, Homward M, Baker EH, Howe FA, et al. Functional MRI demonstrates pain perception in hand osteoarthritis has features of central pain processing. J Biomed Graph Comput. 2013;3(4); doi: 10.5430/jbgc.v3n4p20.

14. Kuchinad A, Schweinhardt $P$, Seminowicz DA, Wood PB, Chizh BA, Bushnell MC. Accelerated brain gray matter loss in fibromyalgia patients: premature aging of the brain? J Neurosci. 2007;27(15):4004-4007; doi: 10.1523/ JNEUROSCI.0098-07.2007.

15. Schmidt-Wilcke T, Gänssbauer S, Neuner T, Bogdahn U, May A. Subtle grey matter changes between migraine patients and healthy controls. Cephalalgia. 2008;28(1): 1-4; doi: 10.1111/j.1468-2982.2007.01428.x.

16. Schabrun SM, Chipchase LS. Priming the brain to learn: the future of therapy? Man Ther. 2012;17(2):184-186; doi: 10.1016/j.math.2011.12.001.

17. Romero Lauro LJ, Rosanova M, Mattavelli G, Convento S, Pisoni A, Opitz A, et al. TDCS increases cortical excitability: direct evidence from TMS-EEG. Cortex. 2014; 58:99-111; doi: 10.1016/j.cortex.2014.05.003.

18. Nitsche MA, Liebetanz D, Tergau F, Paulus W. Modulation of cortical excitability by transcranial direct current stimulation [in German]. Nervenarzt. 2002;73(4):332-335; doi: 10.1007/s00115-002-1272-9.

19. Alonzo A, Brassil J, Taylor JL, Martin D, Loo CK. Daily transcranial direct current stimulation (tDCS) leads to greater increases in cortical excitability than second daily transcranial direct current stimulation. Brain Stimul. 2012; 5(3):208-213; doi: 10.1016/j.brs.2011.04.006.

20. Marlow NM, Bonilha HS, Short EB. Efficacy of transcranial direct current stimulation and repetitive transcranial magnetic stimulation for treating fibromyalgia syndrome: a systematic review. Pain Pract. 2013;13(2):131-145; doi: 10.1111/j.1533-2500.2012.00562.x.

21. O'Connell NE, Cossar J, Marston L, Wand BM, Bunce D, De Souza LH, et al. Transcranial direct current stimulation of the motor cortex in the treatment of chronic nonspecific low back pain: a randomized, double-blind exploratory study. Clin J Pain. 2013;29(1):26-34; doi: 10.1097/ AJP.0b013e318247ec09.

22. Chaturvedi R, Kulandaivelan S, Malik M, Joshi S. Effect of transcranial direct current stimulation (TDCS) on pain in fibromyalgia - systematic review based on Prisma guidelines. Int J Physiol Nutr Phys Educ. 2018;3(2):858862.
23. Hurley MV, Bearne LM. Non-exercise physical therapies for musculoskeletal conditions. Best Pract Res Clin Rheumatol. 2008;22(3):419-433; doi: 10.1016/j.berh.2008. 01.001.

24. Larmer PJ, Reay ND, Aubert ER, Kersten P. Systematic review of guidelines for the physical management of osteoarthritis. Arch Phys Med Rehabil. 2014;95(2):375389; doi: 10.1016/j.apmr.2013.10.011.

25. Teo PL, Hinman RS, Egerton T, Dziedzic KS, Bennel KL. Identifying and prioritizing clinical guideline recommendations most relevant to physical therapy practice for hip and/or knee osteoarthritis. J Orthop Sports Phys Ther. 2019;49(7):501-512; doi: 10.2519/jospt.2019.8676.

26. Chang W-J, Bennell KL, Hodges PW, Hinman RS, Young CL, Buscemi V, et al. Addition of transcranial direct current stimulation to quadriceps strengthening exercise in knee osteoarthritis: a pilot randomised controlled trial. PLoS One. 2017;12(6):e0180328; doi: 10.1371/journal.pone.0180328.

27. Altman R, Asch E, Bloch D, Bole G, Borenstein D, Brandt K, et al. Development of criteria for the classification and reporting of osteoarthritis. Classification of osteoarthritis of the knee. Diagnostic and Therapeutic Criteria Committee of the American Rheumatism Association. Arthritis Rheum. 1986;29(8):1039-1049; doi: 10.1002/art.1780290816.

28. Downs SH, Black N. The feasibility of creating a checklist for the assessment of the methodological quality both of randomised and non-randomised studies of health care interventions. J Epidemiol Community Health. 1998;52(6):377-384; doi: 10.1136/jech.52.6.377.

29. Ahn H, Woods AJ, Kunik ME, Bhattacharjee A, Chen Z, Choi E, et al. Efficacy of transcranial direct current stimulation over primary motor cortex (anode) and contralateral supraorbital area (cathode) on clinical pain severity and mobility performance in persons with knee osteoarthritis: an experimenter- and participant-blinded, randomized, sham-controlled pilot clinical study. Brain Stimul. 2017;10(5):902-909; doi: 10.1016/j.brs.2017. 05.007.

30. Ahn H, Suchting R, Woods AJ, Miao H, Green C, Cho RY, et al. Bayesian analysis of the effect of transcranial direct current stimulation on experimental pain sensitivity in older adults with knee osteoarthritis: randomized sham-controlled pilot clinical study. J Pain Res. 2018;11: 2071-2082; doi: 10.2147/JPR.S173080.

31. Da Graca-Tarragó M, Lech M, Angoleri LDM, Santos DS, Deitos A, Brietzke AP, et al. Intramuscular electrical stimulus potentiates motor cortex modulation effects on pain and descending inhibitory systems in knee osteoarthritis: a randomized, factorial, sham-controlled study. J Pain Res. 2019;12:209-221; doi: 10.2147/JPR.S181019. 